\title{
O Pensamento Computacional e as Tecnologias da Informação e Comunicação: como utilizar recursos computacionais no ensino da Matemática?
}

\author{
Gilson Pedroso dos Santos ${ }^{1}$, José Ricardo e Souza Mafra ${ }^{1}$ \\ Programa de Pós-graduação em Educação - Instituto de Biodiversidade e Florestas - \\ Universidade Federal do Oeste do Pará (UFOPA) \\ Santarém - PA- Brasil \\ \{gilson.santos, jose.mafra\}@ufopa.edu.br
}

\begin{abstract}
This work aimed to investigate the discussion about Computational Thinking (CP) in the Amazonian context, more precisely in the western region of Pará (Santarém municipality), with the help of Information and Communication Technologies (ICT) applied to the teaching of mathematics in basic education. For that, a little of the potential of computer programs such as PhET Interactive Simulations, OpenOffice Calc and Scratch was presented. The results converge to the discussion about how to elaborate activities, involving PC and ICT, that can be applied in the teaching-learning process. There was a significant level of motivation in learning mathematics through computational resources.
\end{abstract}

Resumo. Este trabalho buscou investigar a discussão sobre Pensamento Computacional (PC) no contexto amazônico, mais precisamente na região oeste do Pará (município de Santarém), com o auxílio das Tecnologias da Informação e Comunicação (TIC), aplicados ao ensino da matemática na educação básica. Para tanto, apresentou-se um pouco dos potenciais de programas computacionais como PhET Simulações Interativas, OpenOffice Calc e Scratch. Os resultados convergem para a discussão sobre como elaborar atividades, envolvendo o PC e as TIC, que possam ser aplicadas no no processo de ensino-aprendizagem. Percebeu-se um nível de motivação significativo em aprender matemática através dos recursos computacionais.

\section{Introdução}

As primeiras décadas do século XXI apresentam uma nova dinâmica social, marcada pela utilização das novas tecnologias que transformam diariamente o comportamento das pessoas e sua maneira de ser, tanto a nível local ou regional, quanto a nível global. As novas tecnologias estão presentes em vários aspectos das nossas vidas, exigindo assim, uma especial abordagem na educação. França, Silva e Amaral (2012, p. 282) afirmam que: "Desenvolver práticas educativas que visem à formação do cidadão, aptos a lidar com os desafios do mundo moderno, cada vez mais permeado pelas novas tecnologias da informação e comunicação, torna-se um elemento indispensável quando se pretende promover uma educação de qualidade". 
VII Congresso Brasileiro de Informática na Educação (CBIE 2018)

Anais dos Workshops do VII Congresso Brasileiro de Informática na Educação (WCBIE 2018)

A maneira como deve ocorrer o processo educativo de hoje não deve ser igual como ocorria no século XX. Houve profundas transformações no âmbito político, econômico, cultural, tecnológico, dentre outros. Não se pode considerar a escola como algo isolado da sociedade, sem discutir, refletir e praticar, dentro do ambiente de ensino, as mudanças que ocorreram ao longo dos anos. Dessa forma, deve haver a preocupação de como a escola e os professores lidam com os novos desafios desse século. Sousa (2016, p. 20) reitera que "É essencial que o professor se aproprie de gama de saberes advindos com a presença das tecnologias digitais da informação e da comunicação para que estas possam ser sistematizadas em sua prática pedagógica".

Como exemplo dessas mudanças, pode-se citar a popularização da internet que atinge hoje desde as classes mais privilegiadas aos menos favorecidos. A televisão se tornou um aparelho eletrônico cada vez mais presente na vida dos brasileiros. A telefonia móvel abrange todas as faixas etárias. E o computador? O computador do novo século possui novo design e é talvez o maior representante das transformações que as novas tecnologias proporcionaram às pessoas. Nessa nova dinâmica surge o conceito de Pensamento Computacional que segundo França, Silva e Amaral (2012, p. 1), "Pensamento Computacional é saber usar o computador como um instrumento de aumento do poder cognitivo e operacional humano, aumentando a nossa produtividade, inventividade e criatividade". O Pensamento Computacional além de propor uma maior criatividade, uma melhor cognição e inventividade, pressupõe a utilização de conceitos da ciência da computação. A habilidade de transformar teorias e hipóteses em modelos e programas computacionais, além de executá-los, depurá-los, e utilizá-los para redesenhar processos produtivos, realizar pesquisas científicas ou mesmo aperfeiçoar rotinas pessoais, é uma das mais primordiais habilidades para os cidadãos do século XXI [Blikstein 2008].

Buscou-se entender como o Pensamento Computacional e as Tecnologias da Informação e Comunicação podem auxiliar no processo de ensino-aprendizagem de uma escola localizada no interior da Amazônia. O objetivo principal desse estudo foi investigar como o Pensamento Computacional, relacionado ao contexto amazônico, mais precisamente na região oeste do Pará (município de Santarém), juntamente com o auxílio das Tecnologias da Informação e Comunicação, podem ser aplicados ao ensino da matemática na educação básica.

Como trabalhos relacionados citam-se: Pereira e Siqueira (2016), Geraldes (2017), Ramos (2014), Costa (2015), Bozolan (2016), Kuin (2005) e Stella (2016). Pereira e Siqueira (2016) apresentam uma plataforma disponível na web que objetiva a divulgação e consulta de objetos de aprendizagem que trabalhem o desenvolvimento do "pensar computacionalmente" no ensino. Geraldes (2017) objetiva à identificação nas práticas pedagógicas dos professores da educação profissional e tecnológica sobre quais habilidades relacionadas ao Pensamento Computacional estão sendo desenvolvidas e quais ferramentas servem de apoio a estas práticas e como eles percebem o PC. A pesquisa de Costa (2015) trata da inserção do Pensamento Computacional na Educação de Jovens e Adultos (EJA), aliados ao uso de dispositivos móveis. Além disso, Bozolan (2016), em seu trabalho, fala sobre como as tecnologias emergentes juntamente com juntamente com o Pensamento Computacional podem auxiliar no processo de ensinoaprendizagem. A investigação de Kuin (2005) busca identificar as condições que são favoráveis para a inserção das TIC no ensino público. Mostra que embora haja uma 
VII Congresso Brasileiro de Informática na Educação (CBIE 2018)

Anais dos Workshops do VII Congresso Brasileiro de Informática na Educação (WCBIE 2018)

crescente demanda da sociedade pela utilização das TIC e também pela comunidade escolar, grande parte das escolas não se apropria dela. Já na pesquisa de Stella (2016) analisou-se o uso de recursos tecnológicos associados às disciplinas da grade curricular do ensino fundamental. Além disso, foi utilizada a ferramenta Scratch. Este trabalho apresenta as seguintes seções: TIC e o Pensamento Computacional na Amazônia, Metodologia, Resultados e Discussões e Considerações Finais

\section{TIC e o Pensamento Computacional na Amazônia}

A Amazônia é uma região que necessita profundamente de grandes transformações na educação e na forma como as populações que habitam este território possam interagir com as outras pessoas do globo. Há muita falta de profissionais qualificados para atuar em áreas como educação e saúde, sobretudo, nas localidades distantes dos grandes centros urbanos. Assim, unir o poder das Tecnologias da Informação e Comunicação, para promover uma tecnologia aliada à educação, é uma forma de tentar mudar a realidade de uma região que fica muitas vezes, pelas suas peculiaridades, à margem das mudanças sociais, tecnológicas e educacionais que ocorrem em outras regiões do planeta.

A tecnologia está presente na vida das pessoas em vários aspectos, inclusive na educação. Além da inserção das TIC na educação, é apresentado como algo extremamente relevante o Pensamento Computacional, que é uma das competências tão necessárias, quanto saber ler e escrever, para o exercício pleno da cidadania no século XXI. Esse pensamento é essencial para que o indivíduo possa desenvolver diversas habilidades. Ressalta-se, ainda, a necessidade de se discutir com professores da educação básica sobre como eles podem desenvolver suas práticas pedagógicas, usando as novas tecnologias educacionais e também o Pensamento Computacional, para que possam auxiliar os alunos a desenvolver habilidades e competências tão necessárias no século XXI que estão diretamente relacionadas ao uso das tecnologias. Barcelos e Silveira (2012, p. 9) complementam que "incorporar o Pensamento Computacional à educação básica envolve a análise sistemática de sua potencial sinergia com outras áreas do conhecimento".

Como exemplos de recursos computacionais que podem ser utilizados no ensino, cita-se o Scratch, OpenOffice Calc e o PhET Simulações Interativas. O Scratch, pelo seu caráter lúdico e atrativo, pode também favorecer o processo de ensino-aprendizagem e, torná-lo assim, um processo bem sucedido. O Calc propicia um ambiente de participação interativa entre professores, alunos e ambiente computacional para o desenvolvimento de atividades. Já o PhET traz aplicativos de fácil utilização, permitindo ainda, simular inúmeros eventos relacionados às ciências naturais.

Scaico $(2013$, p. 96) afirma que o "Scratch projeta no aluno a possibilidade de ele se concentrar no exercício do pensamento algorítmico e na criatividade durante a construção das soluções." Assim, a escolha do Scratch se justifica pelo fato desta ferramenta ser uma linguagem de programação que perpassa a simplicidade de ser apenas mais uma linguagem de programação, uma vez que ela pode despertar a capacidade criativa do educando. O Scratch apresenta um ambiente introdutório de ensino que surgiu objetivando introduzir a programação de forma fácil e rápida para as pessoas que não possuem nenhum tipo de experiência em programar [Maloney 2010]. É 
VII Congresso Brasileiro de Informática na Educação (CBIE 2018)

Anais dos Workshops do VII Congresso Brasileiro de Informática na Educação (WCBIE 2018)

uma ferramenta que possibilita o ensino da lógica de uma forma lúdica, atrativa e interativa. $\mathrm{O}$ seu fácil manuseio permite que usuários de diversas faixas etárias possam utilizá-la.

Com o OpenOffice Calc foi possível trabalhar conceitos de uma maneira ampla, com esse programa que é livre e multiplataforma, sendo disponível em versões para Windows, Linux e Mac Os X [Becker 2011]. Dessa forma, justifica-se a escolha desse segundo recurso computacional pelo seu caráter multiplataforma e por ser uma ferramenta de escritório livre, facilitando a sua implantação em escolas públicas que não dispõe de recursos financeiros para pagar a licença de softwares proprietários.

O terceiro programa utilizado foi o PhET Simulações Interativas, desenvolvido pela Universidade do Colorado. O software PhET é um pacote computacional que traz aplicativos desenvolvidos nos ambiente Java e Flash, permitindo a realização de inúmeros simulações de eventos relacionados às ciências naturais como a biologia, física, química, ciência da terra e matemática.

Além disso, o presente trabalho buscou discutir as TIC segundo as abordagens instrucionistas e construcionistas. O Instrucionismo, abordagem mais utilizada ainda nas escolas, baseia-se no princípio de que a ação de ensinar é fortemente relacionada com a transmissão de informação, ou seja, a instrução, ao aluno [Valente 1993]. Essa corrente pedagógica se relaciona com a instrução que o professor passa para o aluno. $O$ computador é usado apenas para transmitir informações aos educandos. Como exemplos pode-se citar manuais, exercícios de múltipla escolha, tutorial, exercício-e-prática, jogo, simulação. Ou seja, no computador são colocadas diversas informações e elas são passadas aos alunos. Essa abordagem é bastante adotada nas escolas brasileiras, quando se trata do uso das TIC. Apesar da necessidade de superá-la, alguns elementos podem ser utilizados para fins educativos.

Já no Construcionismo o aprendizado é visto como uma atitude ativa, na qual o aluno constrói o seu próprio conhecimento mediado pelo professor [Valente 1993]. Segundo essa abordagem, o aluno, através de um determinado software apropriado, aprende ao exercitar uma tarefa de "ensinar" o computador. Essa corrente está ligada à construção do próprio aluno, após as instruções do professor. São exemplos de atividades construcionistas a linguagem de programação LOGO, produção de textos, etc. O professor tem o papel de mediador enquanto o aluno constrói seu conhecimento utilizando o computador por meio da exploração, interação, investigação e descoberta, tornando a aprendizagem mais significativa.

Este trabalho aborda ainda a Educação Matemática, que tem como um dos precursores o educador matemático Ubiratan D'Ambrósio, o qual defende a superação das mazelas matemáticas provenientes de métodos de ensino obsoletos, também conhecidos como tradicionalistas. Ela também se volta para um ensino da matemática, apoiadas em práticas que visam fortalecer e efetivar o aprendizado do aluno, baseadas nas teorias da aprendizagem, no conhecimento multicultural, na interdisciplinaridade e na transdisciplinaridade. D’Ambrósio (1996), relata que a formação de professores de matemática é um dos grandes desafios para o futuro. Ele destaca ainda as características (propostas por Beatriz S. D’Ambrósio) que o professor de matemática deverá possuir no século XXI, como a visão do que vem a ser a matemática; visão do que constitui a 
VII Congresso Brasileiro de Informática na Educação (CBIE 2018)

Anais dos Workshops do VII Congresso Brasileiro de Informática na Educação (WCBIE 2018)

atividade matemática; visão do que constitui a aprendizagem da matemática e visão do que constitui um ambiente propício à aprendizagem da matemática.

Ressalta-se ainda que essa investigação é importante por ser um dos primeiros a propor uma investigação sobre o Pensamento Computacional no contexto amazônico e espera-se que mais pesquisas relacionadas a essa temática possam surgir. Por fim, os resultados obtidos podem ser objetos de reflexão para os educadores de modo geral, principalmente, os que ensinam matemática, para que estes possam inserir o $\mathrm{PC}$ e as TIC nas suas aulas. Embora haja outras pesquisas envolvendo o PC na educação básica, não foi encontrado trabalho relacionado com este, abordando escolas de localidades amazônidas.

\section{Metodologia}

A pesquisa realizada é um estudo de caso e possui elementos característicos da pesquisa participante, uma vez que se busca o envolvimento do pesquisador e dos pesquisados no estudo e a superação da questão norteadora principal deste trabalho. Conforme Gil (2002), "a pesquisa participante, assim como a pesquisa ação, caracteriza-se pela interação entre pesquisadores e membros das situações investigadas". Já Rauen (2002, p. 222), reitera que a pesquisa participante se adequa a trabalhos orientados pela metodologia dialética.

Além disso, para se alcançar os objetivos, foi proposta uma metodologia contendo seis etapas: a) $1^{\text {a }}$ etapa - Pesquisa Bibliográfica (onde foi feito o levantamento, a seleção, o fichamento e o arquivamento de informações relacionadas à pesquisa) e revisão crítica da literatura sobre o tema (baseada em critérios metodológicos, a fim de separar os textos que têm validade daqueles que não têm); b) $2^{\text {a }}$ etapa - Foram observados os alunos na sala de aula, o professor e também o ambiente escolar, com a finalidade de se caracterizar a turma e a escola. Antes da aplicação das oficinas, os alunos e o professor de matemática responderam o questionário sobre o ensino da disciplina e a respeito do processo de ensino como um todo. Foram levantados dados do QEdu, Prova Brasil, IDEB, dentre outros e também analisado o Projeto Político Pedagógico da escola; c) $3^{\text {a }}$ etapa - As oficinas foram planejadas e adaptadas de acordo com o plano de ensino da disciplina de matemática. As oficinas envolveram conteúdos matemáticos através da utilização dos programas PhET Simulações Interativas, OpenOffice Calc e Scratch; d) $4^{\text {a }}$ etapa - Aplicação das oficinas com a turma do sexto ano. Foram aplicadas dez oficinas, onde no final de cada uma delas foi utilizado o Relatório-Avaliação proposto por D'Ambrósio (1996); e) $5^{\text {a }}$ etapa - Avaliação final dos alunos e professor sobre as oficinas. Foi aplicado mais um questionário aos alunos no final das dez oficinas. Além disso, foram entrevistados os alunos, bem como o professor de matemática; f) $6^{\text {a }}$ etapa - Análise e discussão dos resultados. As entrevistas e os relatórios foram analisados para verificar se os objetivos foram alcançados. Os dados obtidos foram analisados, tratados e transformados em informação para que se pudesse refletir sobre o impacto que a pesquisa causou.

Durante as oficinas foram manuseados três programas: Calc, Phet e Scratch. Estes foram alguns instrumentos tecnológicos utilizados e que podem auxiliar o ensino da matemática no ensino fundamental. A aplicação das atividades ocorreu no laboratório de informática da escola pública municipal e contou com a participação de vinte e dois alunos do sexto ano, do professor de matemática da turma e do pesquisador. Foram 
VII Congresso Brasileiro de Informática na Educação (CBIE 2018)

Anais dos Workshops do VII Congresso Brasileiro de Informática na Educação (WCBIE 2018)

realizados dez encontros, onde cada encontro correspondeu a uma atividade e a duas aulas de quarenta minutos.

\section{Resultados e Discussões}

Foram desenvolvidas 10 atividades: 3 atividades utilizando o Calc para aprendizado sobre aritmética; 3 atividades utilizando o Phet para aprendizado sobre Frações; e 04 atividades utilizando o Scratch para aprendizado sobre a lógica matemática.

Foram apresentados tutoriais interativos, exercícios de fixação e relatório de avaliação. Durante a realização das atividades foi verificado que as atividades acima de tudo foram atrativas e interativas para os alunos. Quanto à utilização do RelatórioAvaliação, este mostrou-se um instrumento poderoso de avaliação da aprendizagem. A aplicação dos questionários aos alunos antes do início das atividades possibilitou diagnosticar os conhecimentos prévios que os discentes detinham sobre TIC e pensamento computacional. $\mathrm{O}$ questionário respondido pelo professor trouxe informações de como esse profissional atua no ensino.

Ao utilizarem os recursos computacionais os alunos se sentem mais motivados, como nota-se em: "Eu acho muito bacana estudar na aula de informática, porque podemos mexer nos computadores e sentir à vontade. Gosto de trabalhar na informática, eu aprendo mais e faço o melhor trabalho possivel para agradar os professores (Participante 05)". Essa motivação é muito importante para o processo de ensino-aprendizagem, pois desperta o interesse do aluno para aprender determinado conteúdo. Muitas escolas possuem salas de aula, onde há como recursos o quadro e o giz, negando que além dos muros da instituição, há uma sociedade onde se utilizam maciçamente diversos artefatos tecnológicos. Os alunos quando puderam ter contato com os computadores ficaram muito felizes: "Eu aprendi muitas coisas e acho muito bacana estudar na aula de informática e melhor ainda com computadores (Participante 22)."

Através das TIC como o Calc, foi possível os alunos aprenderem a efetuar diversos cálculos, como a média aritmética: "Aprendi que Open Office pode ser instalado em vários computadores. O open office contem barra de títulos, barra de menus, barra de ferramentas, barra de fórmulas, coluna, linha, caixa de nome. Fizemos a planilha Boletim e aprendemos a fórmula $((B 4+C 4+D 4+E 4) / 4)$ (Participante 06)."

$\mathrm{O} \mathrm{PhET}$ também como recurso computacional possibilitou que os alunos aprendesse sobre frações: "Eu aprendi frações. Ainda bem que aprendi frações no computador. (Participante 12)."

Ao fim das atividades, notou-se certo descontentamento, pois os alunos sabiam que voltariam a ter as aulas tradicionais, embora o professor tenha informado que iria utilizar mais o laboratório de informática para fins de ensino: "Hoje é um dia muito triste, pois é a última aula de informática, mas do mesmo jeito foi bem legal. Eu aprendi sobre Scratch, Calc e várias coisas (Participante 15)."

A realização das aulas fora do espaço convencional, além de motivar, representou uma oportunidade para o professor perceber que o processo de ensinoaprendizagem pode ser mais atrativo, dinâmico e mais efetivo. 
Papert critica a tendência dominante de supervalorização do abstrato e afirma que isso é um obstáculo ao progresso da educação. Ele defende a inversão, onde o progresso intelectual passa do concreto para o abstrato. Essa inversão deve ocorrer tanto no conteúdo quanto no discurso dos educadores, porque o uso concreto de expressão possibilita mostrar e dizer o que se procura comunicar, além de contribuir para um senso mais rico daquilo que torna o pensamento concreto mais poderoso [Papert 2008]. Nas oficinas, ao utilizar os programas, foi oportunizado aos alunos experimentarem essa relação entre o abstrato e o concreto, por exemplo, quando os alunos utilizaram o PhET para conhecerem as frações, através das simulações. O conteúdo foi repassado, mas também vivenciado através de um recurso computacional.

Algumas habilidades propostas por Barr e Stephenson (2011), como decomposição, simulação, reconhecimento de padrões, representação de dados, abstração e algoritmos foram desenvolvidas durante as atividades.

A habilidade de decomposição foi trabalhada, por exemplo, quando para cada ator do Scratch um código foi elaborado. A decomposição é estabelecida como a quebra de problemas maiores em problemas menores e mais fáceis de serem resolvidos [Barr e Stephenson 2011]. Quando o aluno ao criar uma história, animação ou jogo, resolveu criar primeiramente uma parte do código, ele decompôs o problema, ou seja, construiu apenas uma pequena parte que ao juntar-se às outras partes formou um todo com significado e que pode ser executado, gerando um produto final.

A simulação, representação ou modelo de um processo, que pode também envolver experimentos sendo executados, durante as atividades, pode ser percebida na utilização do programa PhET. Nele havia simulações de várias áreas como física, química, dentre outros, mas foi utilizada a matemática. Através das simulações sobre frações, o aluno pode simular diversas formas de utilizar as frações, além de poder visualizar esse conteúdo através de um recurso computacional. A simulação também permitiu que os estudantes pudessem refletir como as frações podem ser aplicadas no cotidiano deles.

O reconhecimento de padrões refere-se à solução de um problema que se repete e identificar uma solução padronizada resolvidos [Barr e Stephenson 2011]. Isso ocorreu quando os alunos construíram seus códigos após fazerem a primeira animação. Os alunos puderam reconhecer como desenvolver a codificação, utilizando esse recurso para desenvolver diversas produções. Já a representação de dados foi uma habilidade que pode ser desenvolvida através do Calc. É um processo onde se representa e se organiza dados através de gráficos, tabelas, imagens, textos ou figuras resolvidos [Barr e Stephenson 2011]. Isso ocorreu na elaboração do Boletim onde os alunos puderam inserir disciplinas e notas, além da média. Esses dados organizados numa planilha, pode mais facilmente gerar informações que serão utilizadas, por exemplo, para o aluno verificar qual disciplina tem melhor desempenho, qual tem pior desempenho, qual a pontuação necessária para não reprovar, dentre outros. Esses dados também podem gerar diversos gráficos.

Os algoritmos, sequência de passos para criação ou resolução de problemas, pode ser observado em: "Aprendi a programar jogos e desenhos e aprendi a mexer no Scratch (Participante 03)"; "A gente entrou em um jogo que nem eu nem a Participante 21 não sabia jogar. Depois a gente entrou no Scratch que é mais ou menos de lógica 
VII Congresso Brasileiro de Informática na Educação (CBIE 2018)

Anais dos Workshops do VII Congresso Brasileiro de Informática na Educação (WCBIE 2018)

que permite que você faça seu próprio jogo (Participante 10)"; "Editamos uns jogos no Scratch (Participante 09)"; "Hoje eu aprendi a mexer no Scratch. Ele nos ajuda a ser mais educativo e o gatinho que tem é um personagem e pode ser baixado em qualquer computador. Na área de script que fizemos a montagem de um código (Participante 12). Os alunos desenvolveram seus algoritmos quando utilizaram os diversos comandos de várias categorias como aparência, movimento, controle, dentre outros, e criaram uma sequência lógica que pode ser executada quando a bandeira verde for clicada.

A abstração, processo necessário para reduzir a complexidade do problema e para definir ideias principais, pode ser observada em todas as atividades, quando por exemplo, ao iniciar as tarefas, o aluno refletiu primeiramente sobre como iria desenvolver determinada tarefa. No Calc, o aluno poderia primeiramente inserir os nomes das disciplinas e logo em seguida as notas, mas optou-se em digitar as disciplinas, os bimestres, depois as notas e em seguida calculou-se a média.

\section{Considerações Finais}

Neste trabalho pode-se concluir que os resultados obtidos apontam para a necessidade do planejamento e efetivação de aulas que possam despertar nos alunos um maior interesse pela disciplina de matemática. Esse planejamento, para ser bem-sucedido e para cumprir seu objetivo de auxiliar de modo satisfatório o processo de ensino e aprendizagem, deve ser produzido pelo professor e por um facilitador que detenha conhecimento sobre os recursos computacionais. Durante a realização da pesquisa foi verificado que as atividades, acima de tudo, foram atrativas e interativas para os alunos. Foram atrativas devido o ambiente de ensino ser um laboratório de informática e não mais uma sala de aula tradicional. Foi interativa porque ao manipular as ferramentas os alunos puderam experimentar os programas e aprender matemática através de uma forma diferente, isto é, por meio das TIC.

Quanto ao uso da TIC no ensino da matemática, isto se mostrou uma poderosa forma de ensinar, devido ser atrativa e interativa para os alunos, além de possibilitar a visualização dos conteúdos de uma maneira mais dinâmica e mais significativa, como por exemplo, visualizar as frações na tela do computador com uma rica qualidade gráfica e não no quadro negro pintado de giz colorido. Em relação ao Pensamento Computacional, pode-se afirmar que o PC é muito relevante, uma vez que ao utilizar o programa Scratch, por exemplo, os alunos puderam criar histórias, jogos, utilizando princípios da lógica computacional, da programação e da lógica matemática. Ao criar e ver sua criação na tela do computador, o aluno desenvolve sua capacidade cognitiva, sua inventividade e sua criatividade, além de contribuir para o desenvolvimento de sua própria autoestima.

Observou-se que a matemática continua sendo uma disciplina que apresenta certa resistência de aprendizado por parte dos alunos, o que indica que reflexões de como se deve ensinar a matemática são necessárias e urgentes. Vale lembrar que as TIC e o Pensamento Computacional podem ser grandes aliados na educação matemática. Como trabalhos futuros sugere-se a investigação de como o Pensamento Computacional pode ser disseminado em escolas públicas em diferentes regiões do país, utilizando-se os mesmos recursos metodológicos. Além disso, é importante verificar quais outros recursos computacionais podem ser utilizados no ensino da matemática. Também se 
recomenda investigar como as TIC e o PC podem colaborar para a formação inicial e continuada dos professores.

A Escola (professores, alunos, direção, coordenadores, pais e comunidade em geral) precisam se apropriar das TIC, numa perspectiva de inclusão digital, porque se encontram numa época em que tudo está conectado e a escola é o lugar por onde todas as crianças passam; numa perspectiva de inclusão social, porque dominar as novas tecnologias estão em todos os setores da sociedade e cada vez mais alcançam novos espaços. A Escola também deve refletir sobre o PC no ensino e como este pode contribuir para uma educação melhor. Para isso, há muitos desafios, como aproveitar melhor os laboratórios de informática, numa forma que os alunos possam utilizá-los para aprender e o professor para melhorar sua prática.

Por fim, vale ressaltar que há muito que se fazer para se ter uma educação mais igualitária, justa, democrática, emancipatória e que possibilite a formação de indivíduos críticos, pensantes e atuantes na transformação de sua comunidade.

\section{Referências}

Barcelos, T. S.; Silveira, I . F.. Pensamento Computacional e educação matemática: Relações para o ensino de computação na educação básica. In: XX Workshop sobre Educação em Computação, Curitiba/Paraná. Anais do XXXII CSBC. 2012. p. 23.

Barr, V., \& Stephenson, C. Bringing computational thinking to K-12: what is Involved and what is the role of the computer science education community? Acm Inroads, v. 2, n. 1, p. 48-54, 2011.

Becker, D. O Calc como ferramenta para o ensino da matemática. Programa de desenvolvimento educacional do Paraná. 2011. Disponível em $<$ http://www.diaadiaeducacao.pr.gov.br/portals/cadernospde/pdebusca/producoes_pde /2010/2010_unioeste_mat_pdp_dejane_becker.pdf $>$. Acesso em: 06 jun. 2016.

Blikstein, P. O Pensamento Computacional e a reinvenção do computador na educação. 2008. Disponível em <http://www.blikstein.com/ paulo/documents/ online/Ol_pensamento_Computacional.hml>. Acesso em: 05 set. 2017.

Bozolan, S. M. O pensamento computacional: ensino e aprendizagem através do software processing. 2016. 145 f. Dissertação (Mestrado em Tecnologia da Inteligência e Design Digital) - Programa de Estudos Pós-Graduados em Tecnologia da Inteligência e Design Digital, Pontifícia Universidade Católica de São Paulo, São Paulo, 2016.

Costa, B. V. B. Pensamento computacional na Educação de Jovens e Adultos: um estudo de caso utilizando dispositivos móveis. 2015. ix, 98 f., il. Monografia (Licenciatura em Ciência da Computação) - Universidade de Brasília, Brasília, 2015.

Duarte, N. A teoria da atividade como uma abordagem para a pesquisa em educação. Perspectiva, Florianópolis, v.21, n.2, p.229-301. jul./dez. 2003.

D'Ambrosio, U. Educação Matemática: da teoria à prática. Campinas: Papirus Editora, 1996. 
VII Congresso Brasileiro de Informática na Educação (CBIE 2018)

Anais dos Workshops do VII Congresso Brasileiro de Informática na Educação (WCBIE 2018)

Duarte, N. A teoria da atividade como uma abordagem para a pesquisa em educação. Perspectiva, Florianópolis, v.21, n.2, p.229-301. jul./dez. 2003.

França, R. D., Silva, W. D., \& Amaral, H. D. Ensino de Ciência da Computação na Educação Básica: Experiências, Desafios e Possibilidades. In: XX Workshop sobre Educação em Computação, Curitiba. Anais do XXXII CSBC, 2012.

Geraldes, W. B. O Pensamento Computacional no ensino profissional e tecnológico. 2017. 81 f. Dissertação (Mestrado em Gestão do Conhecimento e Tecnologia da Informação) - Pós-Graduação Stricto Sensu em Gestão do Conhecimento e Tecnologia da Informação - Universidade Católica de Brasília, Brasília, 2017.

Gil, A. C. Como elaborar projetos de pesquisa. São Paulo: Atlas, v. 5, p. 61, 2002.

Kuin, S. Condições favoráveis para a apropriação de tecnologias de informação e comunicação na escola. Dissertação (Mestrado em Educação) Pontifícia Universidade Católica de São Paulo, São Paulo. 2005.

Maloney, J., Resnick, M., Rusk, N., Silverman, B., \& Eastmond, E. The scratch programming language and environment. ACM Transactions on Computing Education (TOCE), v. 10, n. 4, p. 16, 2010.

Papert, S. A máquina das crianças: repensando a escola na era da informática. Tradução de Sandra Costa. Porto Alegre: Artes Médicas, 2008.

Pereira, L. C., \& Siqueira, S. W. M. Programe-se: O Pensamento Computacional na Educação Básica. 2016. Disponível em:< http://www.ituiutaba.uemg.br/ seminario/siteoriginal/index2.html>. Acesso em: 15 ago. 2017.

Ramos, H. D. A. Pensamento computacional na educação básica: uma proposta de aplicação pedagógica para alunos do quinto ano do ensino fundamental do Distrito Federal. 2014. vii, 52 f., il. Monografia (Licenciatura em Ciência da Computação) - Universidade de Brasília, Brasília, 2014.

Rauen, F. J. Roteiros de investigação cientifica. Tubarão, SC: Unisul, 2002.

Scaico, P. D., de Lima, A. A., Azevedo, S., da Silva, J. B. B., Raposo, E. H., Alencar, Y., ... \& Scaico, A. Ensino de programação no ensino médio: Uma abordagem orientada ao design com a linguagem Scratch. Revista Brasileira de Informática na Educação, v. 21, n. 02, p. 92, 2013.

Stella, A. L. Utilizando o Pensamento Computacional e a computação criativa no ensino da linguagem de programação Scratch para alunos do ensino fundamental. Dissertação (Mestrado em Tecnologia) - UNICAMP, Limeira, 2016.

Valente, J. A. Diferentes usos do Computador na Educação. 1993. Disponível em:<http://www.mrherondomingues.seed.pr.gov.br/redeescola/escolas/27/1470/14/ar quivos/File/PPP/Diferentesusosdocomputadoreducacao.PDF $>$. Acesso em: 13 out. 2017. 